\title{
Editorial
}

\section{Public health nutrition interventions can be simple and effective}

In the May editorial, the lack of good intervention papers was noted and we promised an article on writing such a paper. In this issue we have focused on interventions, including a relatively simple workplace intervention to increase fruit consumption, capacity building interventions, and an evaluation of a policy to improve food quality in English schools. It is likely that a combination of diverse approaches such as these will be necessary to have lasting and significant impacts on public health nutrition.

Some of the most effective interventions are very simple. In this issue, Alinia et al. ${ }^{(1)}$ demonstrate how putting fruit in an accessible spot in the workplace increased intakes of fruit and fibre and decreased the intake of added sugar. This was achieved without additional health education or promotion effort. In a similar vein, Bucher et al. ${ }^{(2)}$ show that when people were offered two vegetables rather than one, they served themselves more vegetables. Because Boucher's study used replica foods, it is not clear whether the larger serving of vegetables would translate to greater intakes. The above studies are examples of simple approaches that could be applied in many situations and warrant further investigation.

At the policy level, the paper by Matthews et $a l^{(3)}$ in this issue seeks to evaluate the effect on school food and beverage vending of the 2007 food-based standards for school food other than lunch. This was done by means of mailed surveys in English secondary schools, before and after the legislation was introduced. The findings suggest that the new legislation has contributed to an improved quality of food available and decreased its provision from vending machines.

A diverse range of papers relating to capacity building interventions has also been included in this issue. These relate not just to capacity building within the public health nutrition workforce, as described by Palermo et $a l^{(4)}$ and Fox and Beyers ${ }^{(5)}$, but also within communities. An example of the latter is provided by Bezner Kerr et $a l^{(6)}$ in their intervention to improve child growth rates in Malawi by providing education not only on nutrition but also on the use of legume crops along with the staple cereal, maize. Production of legumes as an additional nutritious crop has the added benefit of building up the soil to improve the maize crop. Despite some limitations in the study design and analysis, there was evidence to support an improvement in nutritional status in children related to the length of time and intensity of participation in the intervention. Konstantyner et al $^{(7)}$ report on the impact of training educators on the health of children in day-care centres in Sao Paulo, Brazil, as assessed by the prevalence of anaemia. At the beginning of the trial, approximately $36 \%$ of the children were anaemic and training the child-care educators appeared to reduce the risk of anaemia, after controlling for other risk factors.

These studies offer a wide range of approaches that should be considered as means to improve nutrition at the population level. Other studies in this issue include more work on anaemia ${ }^{(8,9)}$, capacity building ${ }^{(10,11)}$, vending machines in schools ${ }^{(12)}$, a pilot of a workplace intervention to reduce salt intake ${ }^{(13)}$, and a study of pledges from the food industry regarding marketing food to children ${ }^{(14)}$. The latter study by Hawkes and Harris notes that despite a lot happening recently, there is a long way to go. Highlighting the importance of food advertising to children, the study by Jones and Kervin ${ }^{(15)}$ in Australia finds that short-term exposure to food advertisements influenced children's food choice immediately afterwards.

We hope you enjoy this selection of papers and are inspired by the achievements of these authors.

Agneta Yngve Editor-in-Chief

Allison Hodge

Marilyn Tseng

Irja Haapala

Geraldine McNeill

Deputy Editors

\section{References}

1. Alinia S, Lassen AD, Krogholm KS et al. (2011) A workplace feasibility study of the effect of a minimal fruit intervention on fruit intake. Public Health Nutr 14, $1382-1387$.

2. Bucher T, van der Horst $K \&$ Siegrist M (2011) Improvement of meal composition by vegetable variety. Public Health Nutr 14, 1357-1363.

3. Matthews A, Nelson M, Kaur A et al. (2011) Where has all the chocolate gone? A national survey assesses the effects of recent legislation to improve the nutritional quality of English secondary-school vending. Public Health Nutr 14, 1394-1402.

4. Palermo C, Hughes R \& McCall L (2011) A qualitative evaluation of an Australian public health nutrition workforce development intervention involving mentoring circles. Public Health Nutr 14, 1458-1465.

5. Fox A \& Beyers J (2011) Planning a graduate programme in public health nutrition for experienced nutrition professionals. Public Health Nutr 14, 1479-1488.

6. Bezner Kerr R, Berti PR \& Shumba L (2011) Effects of a participatory agriculture and nutrition education project on 
child growth in Northern Malawi. Public Health Nutr 14, 1466-1472.

7. Konstantyner T, Taddei JA, Oliveira MD et al. (2011) The impact of training for day-care educators on childhood anaemia in nurseries: an institutional randomised clinical trial. Public Health Nutr 14, 1450-1457.

8. Kersey M, Chi M \& Cutts DB (2011) Anaemia, lead poisoning and vitamin D deficiency in low-income children: Do current screening recommendations match the burden of illness? Public Health Nutr 14, 1424-1428.

9. Pacey A, Weiler H \& Egeland GM (2011) Low prevalence of iron deficiency anaemia among Inuit preschool children: Nunavut Inuit Child Health Survey, 2007-2008. Public Health Nutr 14, 1415-1423.

10. Parker W, Steyn NP, Levitt NS et al. (2011) They think they know but do they? Misalignment of perceptions of lifestyle modification knowledge among health professionals. Public Health Nutr 14, 1429-1438.
11. Jonsdottir S, Hughes R, Thorsdottir I et al. (2011) Consensus on the competencies required for public health nutrition workforce development in Europe - the JobNut project. Public Health Nutr 14, 1439-1449.

12. Minaker LM, Storey KE, Raine KD et al. (2011) Associations between the perceived presence of vending machines and food and beverage logos in schools and adolescents' diet and weight status. Public Health Nutr 14, 1350-1356.

13. Geaney F, Harrington J, Fitzgerald AP et al. (2011) The impact of a workplace catering initiative on dietary intakes of salt and other nutrients: a pilot study. Public Health Nutr 14, 1345-1349.

14. Hawkes C \& Harris J (2011) An analysis of the content of food industry pledges on marketing to children. Public Health Nutr 14, 1403-1414.

15. Jones SC \& Kervin L (2011) An experimental study on the effects of exposure to magazine advertising on children's food choices. Public Health Nutr 14, 1337-1344. 